\title{
Review Article \\ Silk Fibroin: A Promising Tool for Wound Healing and Skin Regeneration
}

\author{
M. Vidya $\mathbb{( D}^{1}$ and Senthilkumar Rajagopal $\mathbb{D}^{2}$ \\ ${ }^{1}$ Dept of Chemistry and Biochemistry, MS Ramaiah College of Arts, Science and Commerce, Bangalore, India \\ ${ }^{2}$ Dept of Biotechnology, School of Applied Sciences, REVA University, Bangalore, India \\ Correspondence should be addressed to Senthilkumar Rajagopal; senthilanal@yahoo.com
}

Received 3 July 2021; Revised 12 September 2021; Accepted 14 September 2021; Published 1 October 2021

Academic Editor: Domenico Acierno

Copyright (C) 2021 M. Vidya and Senthilkumar Rajagopal. This is an open access article distributed under the Creative Commons Attribution License, which permits unrestricted use, distribution, and reproduction in any medium, provided the original work is properly cited.

\begin{abstract}
Silk is a functional protein biomaterial produced by a variety of insects like flies, silkworms, scorpions, spiders, and mites. Silk synthesized by silkworms is extensively studied for its applications in tissue engineering and wound healing. Silk is undoubtedly a natural biocompatible material with humans and has its role in medical treatments from ancient times. The silk worm protein comprises two types of proteins namely fibroin and sericin. Silk fibroin makes up approximately $70 \%$ of cocoon weight and has wide applications in textiles and in all biomedical applications owing to its biocompatible, nontoxic, biodegradable, less immunogenic, and noncarcinogenic nature. It possesses outstanding toughness and mechanical strength, while silk sericin possesses high defensive ability against ultraviolet light and oxidation. Silk fibroin has been known to induce wound healing by increasing cell proliferation and growth and migrating various types of cells which are involved in different stages of wound healing process. With several silk varieties like silk worm fibroin, silk sericin, recombinant silk materials, and native spider silk have been investigated for its wound healing applications over the last several decades. With an objective of harnessing the silk regenerative properties, plentiful strategies have been studied and applied to develop bioartificial skin grafts and bioactive wound dressings in recent times. This review gives a detailed insight into the structure, general properties, fibroin structure-properties relationship, and biomedical applications of silk fibroin.
\end{abstract}

\section{Introduction}

Silks are common protein polymers produced by various insects such as silkworms, spiders, and bees. Silk fibres from various species have varying fibroin sequences, structural properties, and primary sequences. The major part of silk is produced by two types of silkworm: no mulberry (wild variety) and domesticated mulberry. Mulberry silk is produced by the domesticated silkworm family Bombyx mori (B. mori). Eri (Philosamia ricini/Samia ricini), Muga (Anthrraea asanalassamensis), and Tussar (Antheraea mylitta) are the primary sources of wild variety/Saturniidae/nonmulberry silk [1]. Spider silks have a higher mechanical strength than silkworm silk. However, because spider silks are in shortage, domestic Bombyx mori filaments are the most widely used in the commercial silk business [2]. Only silk from silkworms has been manufac- tured on a large scale in the past, and it has lately been employed as a biomaterial due to its long-lasting characteristics and availability [3].

1.1. Silk Fibroin's Structure and Properties. Fibroin and sericin are the two proteins found in silk from the Bombyx mori silkworm: The former is found in the inside of the thread and accounts for roughly $70 \%$ of the silk's weight, while the latter is located in the thin layer that surrounds the interior thread and accounts for the remaining 30\% and also possesses fat/wax (0.8-1\%) and colour/ash (1-1.4\%) [4]. Fibroin is produced by the silkworm's posterior gland, while sericin is released by the silkworm's middle and anterior glands, the morphology of which is shown in Figure 1.

Silk is a natural protein polymer that has been recognized by the US Food and Drug Administration (FDA) for 
medical usage. Silk fibroin is m4ade from mulberry silk after the outermost silk sericin is removed, which has the ability to activate an immune response when combined with fibroin $[6,7]$. While spinning, the larvae releases two very thin $(10 \mu \mathrm{m}$ diameter) fibroin double strands through the spinnerets, simultaneously bonding them together with sericin from the two exocrine silk glands (aligned on both sides of the body). The protein fibre gets stronger and tougher in the presence of air [8].

The major component of silk is fibroin, which serves as the inner core and gives mechanical strength, whereas sericin serves as the exterior glue-like coating. Two silk fibroin filaments are covered with sericin in each silk fibre [9]. It is already been postulated that silk fibroin filaments are made up of $3.5 \mathrm{~nm}$ diameter nanofibrils, which are the building elements of silk.

These nanofibrils intertwine and have a strong interaction with one another and form into bigger fibril units, known as microfibrils that are $20-200 \mathrm{~nm}$ in diameter [10]. Parallel to the silk fibroin filaments, microfibrils and nanofibrils are arranged. The major structural protein of silk is silk fibroin, which includes polypeptide chains with molecular weights ranging from 200 to $350 \mathrm{kDa}$. Silk fibroin's primary structure consists of an H-L complex made up of a light- (L) chain polypeptide and a heavy- $(\mathrm{H}-)$ chain polypeptide joined together by a single disulphide bond at the Cterminus of the H-chain. Furthermore, glycoprotein P25 which is noncovalently connected to the H-L-chains is present in the structure of silk fibroin and contributes to its overall integrity. The $\mathrm{H}$-chain is primarily responsible for the silk fibres fibrous properties. The most common amino acids present in this chain are glycine (46 percent), serine (12 percent), and alanine (30 percent) [11]. Isoleucine, leucine, valine, and other acidic amino acids are mostly found in the nonfibrous L-chains [12].

Because of its biocompatibility, gradual disintegration, low immunogenicity, adaptability, and outstanding mechanical qualities, silk fibroin is increasingly being studied for biomedical applications [13-15]. Silk fibroin has a stronger ability to modify in response to one's biological surroundings, which could lead to better integration and possibly less material-associated thrombosis [16]. This opens up the possibility of using silk motifs as the foundation for biomaterials with specific characteristics. Historically, functional qualities have been associated with specific amino acid patterns [17] and can be genetically and/or chemically manipulated while preserving important secondary structural traits, resulting in recombinant silk polymers which control (i) chemical reactivity, (ii) polymer size, and (iii) characteristics of bulk materials [18]. Silk fibroin has been proven to stimulate adhesion of stem cells, propagation and differentiation in vitro, enhance tissue healing, and inhibit pathological adherence in vivo in various formats (fibres, films, nets, etc.) [19-21]. Silk fibroin (SF) is composed by alanine, serine, and glycine in different percentages. Because of its hydrophobic regions, silk fibroin is high in $\beta$-sheet patterns, which impact its mechanical characteristics, biodegradation rate, and ability to enhance cell adhesion and differentiation in mesenchymal stem cells.

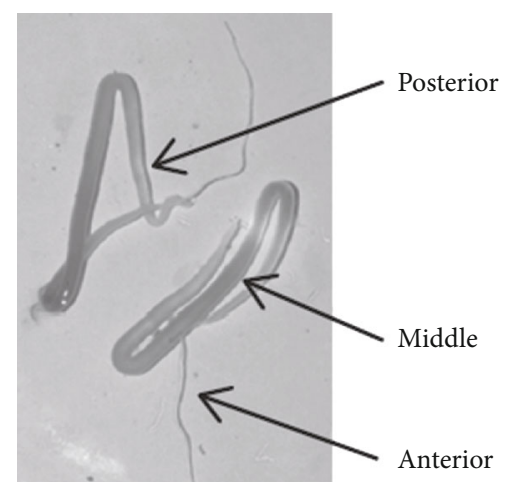

FIGURE 1: Silk gland morphology in Bombyx mori [5].

Silk fibroin is made up of both amorphous and crystalline domains. Gly-Ala repetitions are distributed throughout the crystalline domains via motifs containing tyrosine and serine amino acids. Amorphous domains are made up of bulky side chain amino acids like aspartic acid. The noncrystalline part contributes to the fibre's flexibility and elasticity, while the crystalline part adds to its strength and toughness. For Bombyx mori crystalline structures of silk fibroin, silks I, II, and III are the three conformations which are considered. Silk I is a water soluble version of silk fibroin that has a lot of $\alpha$-helix that can be easily converted into silk II having a $\beta$ sheet structure that is antiparallel [22-24]. The unusual structural conformation of silk fibroin provides mechanical strength and flexibility [6]. Degradation studies of silk fibroin in phosphate-buffered saline for 12 weeks have shown the transition of construct from $\beta$-sheet to random coil, lowering the adhesion force and Young's modulus of the construct [25]. The $\beta$-sheet crystallization has been stimulated in silk-based scaffolds using a variety of approaches. Ethanol and methanol are two popular inorganic solvents that stimulate the development of $\beta$-sheets to a degree of $55 \%$ and $36 \%$, respectively $[26,27]$. Steam autoclaving at high temperature and pressure, on the other hand, induced the greatest $\beta$-sheet crystallinity (60 percent) [28]. Another approach that generated $\beta$-sheet $(30 \%)$ production when mixed with a large proportion of silk I helical structure is water annealing at ambient temperature [29]. A single systemic procedure involving temperature-controlled water vapour annealing from $4^{\circ} \mathrm{C}$ to $100^{\circ} \mathrm{C}$ was employed to fully control the structure and properties of silk. Different kinds of silk conformations like silk I and silk II with controlled $\beta$-sheet may be made using this technology, and the degradability, mechanical strength, and biological response can be regulated [26]. Heat treatment of silk films and fibres has been examined in several lab studies. The colour, crystallinity, and mechanical strength of the silk were all changed when the temperature was raised [30, 31]. The crystallinity, mechanical strength, and colour of the silk were all modified when the temperature was raised. Several researchers have studied at the thermal treatment of silk films and fibres [30-32].

The structure of silk was highly converted to $\beta$-sheet, which is prevalent in Bombyx mori cocoon fibres, when the casted silk films were heated to $100^{\circ} \mathrm{C}$. Furthermore, 
increasing the temperature of the oriented silk fibres above the transition temperature resulted in the creation of $\beta$-sheet conformation over $\alpha$-helical structure [33]. At a temperature of around $140^{\circ} \mathrm{C}$, a solid-state conformational change from an $\alpha$-helical structure to $\beta$-sheet silk II structure happened. The films exhibited that endothermic melting peak followed an exothermic crystallization peak, both near $140^{\circ} \mathrm{C}$, according to modulated differential scanning calorimetry (DSC). Following heating above the structural transition temperature, $\beta$-sheet fibres with a structure comparable to $B$. mori cocoon fibres were generated (Figure 2) [32].

As a result, the structure and mechanical strength of silkbased substrates may be controlled by varying the temperature. Silk fibroin has also been utilised in the manufacturing of textiles and clinical sutures for generations [34]. Primary cells and cell lines can attach to, proliferate in, and differentiate in silk fibroin materials [35] and can be easily used to prepare mats [36], porous scaffolds [37], gels [38], and films [39].

\subsection{Compatibility of Silk Fibroin as a Wound Healing} Biomaterial. The human body's skin serves as a barrier against the infectious agents, dehydration, and environment. Wound healing is a complex process including interactions with many cells and matrices, as well as multiple overlapping phases like inflammation, new tissue creation, and tissue remodelling happening at the same time [41]. The initial phase of wound healing is inflammation, which occurs shortly after an injury and can persist up to two days. To prevent further fluid and blood losses, remove dying and dead tissues, and stop infection, the coagulation cascade, inflammatory pathways, and immune system must all be activated. Inflammatory cells like macrophages and neutrophils play a number of important roles in the repair process, including phagocytosis and the production of many cytokines and growth factors [42]. The second phase of wound healing is new tissue development that is correlated with deposition of collagen/matrix, reepithelialization, angiogenesis, and contraction of wounds $[42,43]$. The remodelling or maturation phase of the wound healing process, which can last for a year or longer depending on the degree of the injury, is combined with the rebuilding of the epidermis and extracellular matrix $[43,44]$.

Skin regeneration is still the target of skin repair in order to minimise the long-term effects of scarring on an individual [45]. Wound healing in mammals is a reparative process that culminates in scar formation rather than a regenerative process that replaces normal tissue architecture [46]. Scar tissue is inferior to normal tissue in terms of function and appearance. It is caused by an excess of extracellular matrix (ECM) being produced following an injury [47]. Collagen I, an important protein influencing the ECM architecture during wound healing, is synthesized majorly by fibroblasts, and its synthesis is majorly regulated by cytokine transforming growth factor $\beta_{1}(\operatorname{TGF} \beta)_{1}[48,49]$. $(\operatorname{TGF} \beta)_{1}$ which is secreted in inactive form is converted to active form enzymatically in order to execute its effect. (TGF $\beta)_{1}$ changes the morphology of many cells like fibroblasts by stimulating polymerisation of the globular form of active cytoskeleton to filamentous form [48].
There really are numerous wound dressing biomaterials on the market today, to mention a few are chitosan [50], hydrocolloids [51], polyurethane [52], alginates [53], collagen $[54,55]$, and hyaluronic acid (Figure 3) [56]. The most widely revealed tissue engineering technique to date is still Integra, a skin substitute, which is a mix of multiple ECM proteins. The utilization of composite tissue engineering skin could be considered to speed up the second stage of repair using Integra [57].

The following characteristics should be present in an ideal wound dressing: (a) preservation of a moist wound area, (b) prevention of desiccation and excessive exudate absorption, (c) permeability of gas, (d) avoidance of bacterial infection and transmission of diseases, and (e) resistance to water [58]. The creation of optimal wound dressings, on the other hand, is still ongoing.

\section{Different Forms of Silk Fibroin for Wound Healing Operations}

2.1. Silk Fibroin Solution. The silk cocoon was degummed in an aqueous solution of $0.02 \mathrm{M} \mathrm{Na}_{2} \mathrm{CO}_{3}$ for 40 minutes boiling at $95^{\circ} \mathrm{C}$, then washed with distilled water to remove the glue-like sericin proteins yields silk fibroin solution [60-62]. Degummed silk fibroin was then solubilized for 50 minutes at $98^{\circ} \mathrm{C}$ with calcium chloride, ethanol, and water (at a molar ratio of $1: 2: 8$ ). This solution was subsequently filtered for three days over dialysis membrane to obtain silk fibroin solutions. Silk fibroin solution greatly induced healing effect both in vitro and in vivo, according to Park et al. [63]. Solubilized silk protein has also been used as an eye drop to help rabbit corneal epithelial wound repair [64].

2.2. Nanofibrous Scaffolds from Silk Fibroin. Silk fibroin scaffolds are an intriguing type of skin substitute made from silk fibroin. Electrospinning creates a pseudo-three-dimensional structure for cell adhesion and growth [60, 65-67]. Twodimensional scaffolds produced through electrospinning technique play an important role in the manufacturing of skin substitute products which comprises all the qualities for a successful skin regeneration and wound closure [68]. Only electrospinning may confer antimicrobial activity, which is based on the movement of ionic species from the fibres, and thus produces wound dressing scaffolds or materials for long-time controlled release [69]. Fabrication of electrospun nanocomposite fibres by in situ silica gelation in poly e-caprolactone solution serves as a promising multibio functional material for orthopaedic applications [70]. The three-dimensional structure of nanofibrous materials supports attachment of the cell and growth of the cell and controls the cell differentiation functions [71]. The electrospun composite nanofibrous scaffolds increased the osteogenic differentiation and proliferation of mesenchymal stem cells in human and human endothelial cells angiogenic activity in vitro [72]. The biodegradable nonwoven poly (lactic-co-glycolic acid) scaffolds developed using electrospinning may improve the anisotropic and isotropic growth of cardiomyocytes [73]. Hollow electrospun nanofibrous structures manufactured by coaxial electrospinning may be a 


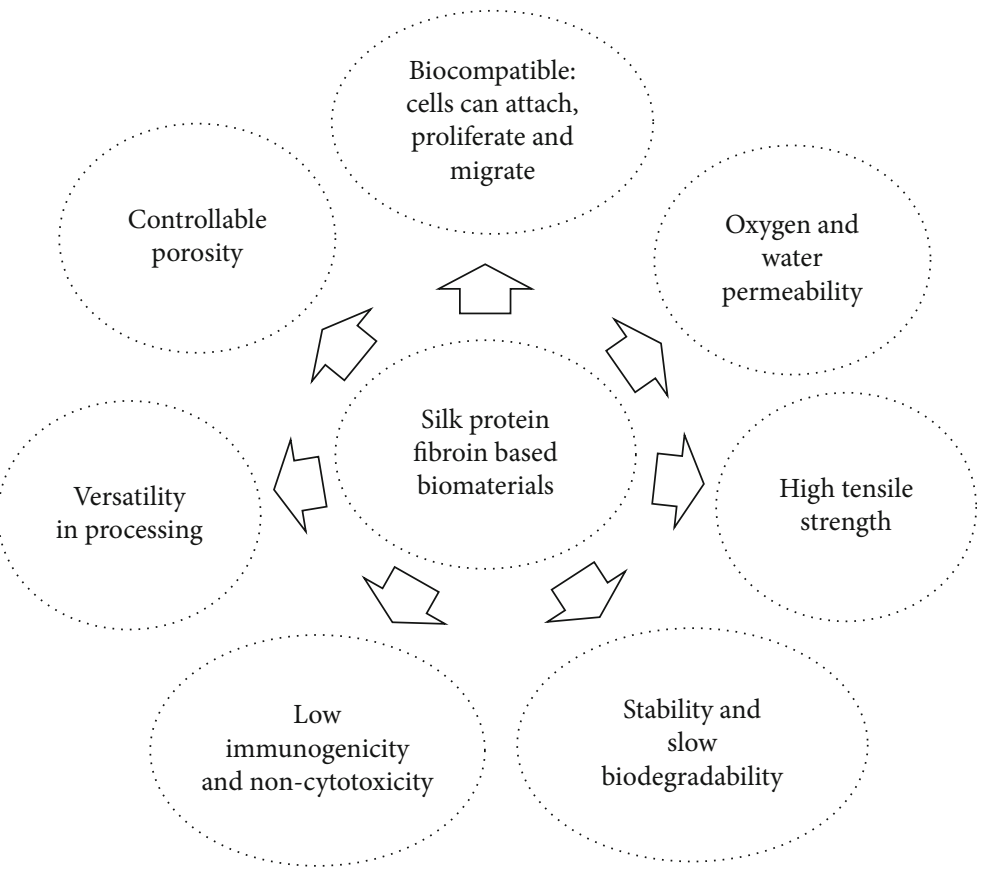

FIGURE 2: Diverse characteristics of biomaterials based on silk protein fibroin (adopted from Naskat et al. [40]).

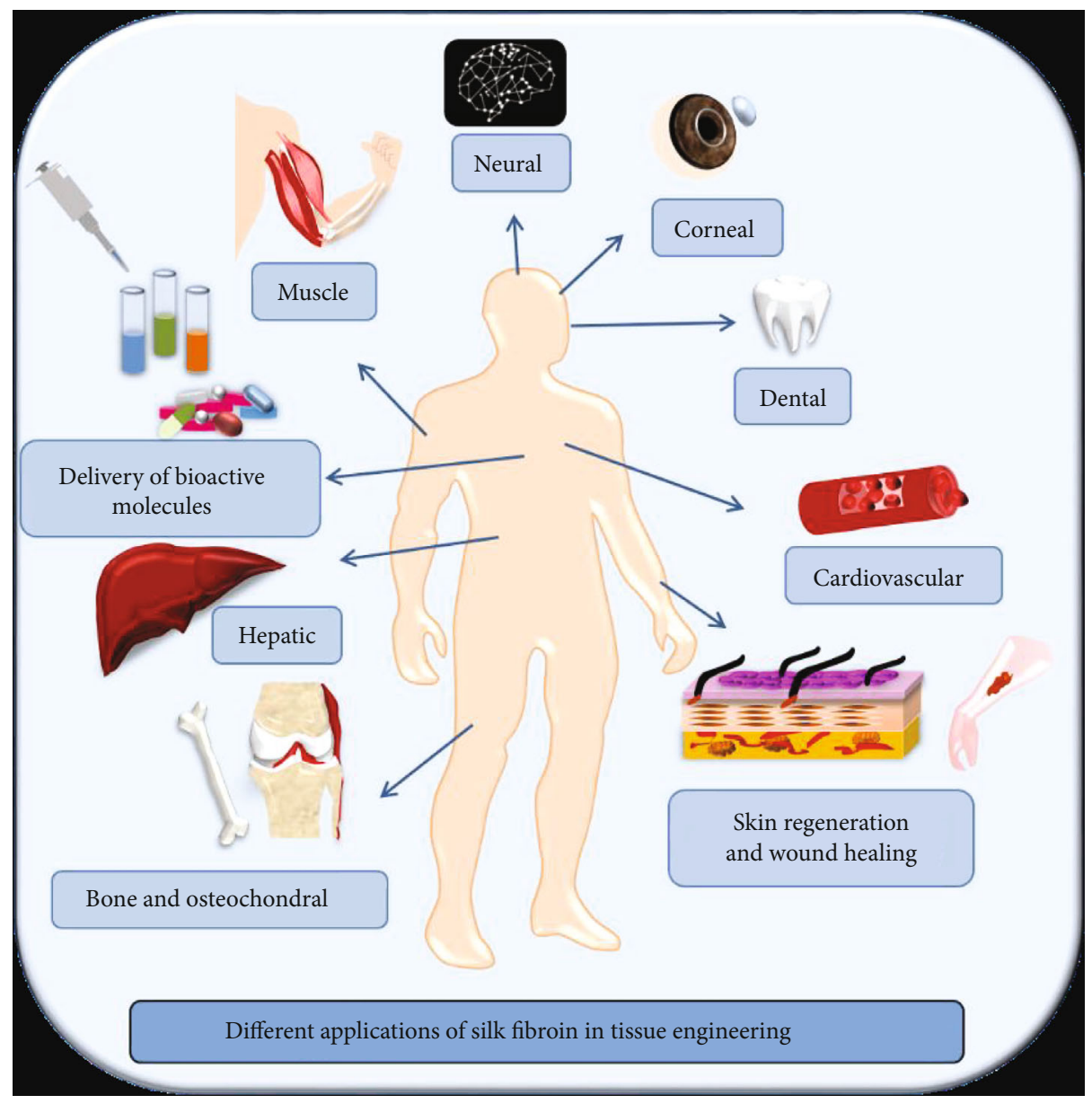

FIGURE 3: Silk fibroin: applications in tissue engineering and regenerative medicine (adopted from Gholipourmalekabadi et al. [59]). 
TABLE 1: Silk fibroin morphologic forms for different wound treatments.

\begin{tabular}{lcc}
\hline Forms of fibroin & Wound type & References \\
\hline \multirow{2}{*}{ Fibroin in solution } & Skin wound with partial thickness & \\
& Burn injury & {$[63,101,102]$} \\
Hydrogel & Corneal epithelial wounds & Burn injury \\
& Scrape wound & {$[86,95]$} \\
Film & Skin wounds with full thickness & {$[100]$} \\
Fibroin sponge & Acute dermal wound & {$[55]$} \\
\hline
\end{tabular}

promising method for drug encapsulation, which enables high drug-loading capacity and augmented solubilization of nonsoluble drugs [74].

The biological and mechanical properties of the electrospun silk fibroin (ESF) mat are directly influenced by the concentration of silk fibroin in the spinning fluid. In an in vitro and ex vivo wound model, electrospun silk fibroin with smaller size nanofibres had a stronger effect on extracellular matrix production and skin cell proliferation [75]. To develop electrospun scaffolds with biomechanical properties similar to natural skin, the fabrication process must be optimised. Research findings established increased proliferation of cells cultured on micron-sized fibres [76-78]. Cells may perceive these scaffolds as two-dimensional structures and may also allow rapid cell proliferation. Scaffolds made of this morphology of fibres may cause cells to adopt an artificial morphology, which may affect the expression of cell adhesion and migration genes and tension-sensitive expression pathways. These may be especially important in preventing pathological scarring or contracture during cutaneous wound healing $[78,79]$. Cells became elongated along the fibre lengths, an aspect that may be useful to utilise for other applications where this morphology may be beneficial, including nerve tissue engineering $[80,81]$.

2.3. Hydrogels from Silk Fibroin. In an aqueous solution, hydrogels are three-dimensional polymeric networks with a high swelling ratio. Hydrogels are typically made from naturally occurring polymers, such as chitosan [82], alginate [83], collagen [84], hyaluronic acid [85], and silk fibroin $[86,87]$ due to their relatively good biocompatibility. Hydrogels have been widely used in a variety of biomedical applications, including wound healing [88]. The beneficial benefits of silk fibroin include not only inducing cell attachment, development, migration, proliferation, and creation of extracellular matrix but also improving the mechanical strength of hydrogels made from other natural polymers [89].

The wild silkworm fibre's mechanical properties such as toughness and extensibility of fibroin fibres are greater than polymers such as Kevlar and elastin [6,90]. Collagen and silk fibroin fibrils possess a suitable interfacial adhesion, and the combined scaffolds display enhanced mechanical properties [91]. In order to couple the biological performance of collagen and mechanical resistance of fibroin,

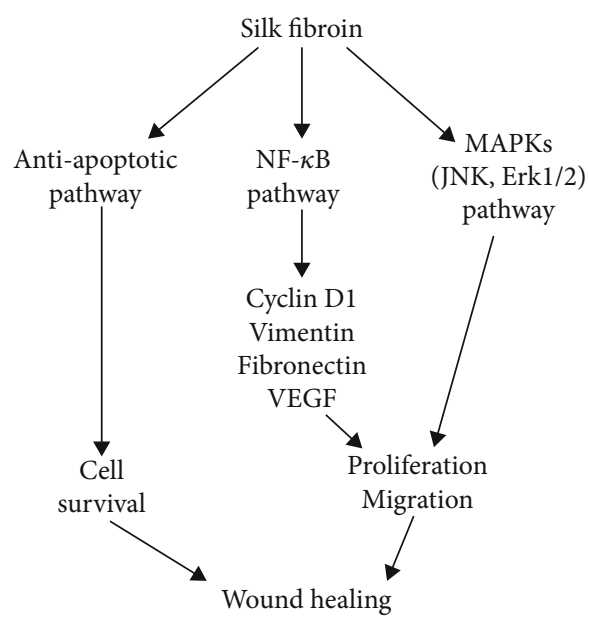

Figure 4: Biological pathways activated by silk fibroin to promote wound healing via enhancing cell viability, cell proliferation, and migration (adopted from Sultan et al. [110]).

new scaffolds were designed for vascular tissue engineering applications. The results highlighted that addition of silk fibroin fibres in collagen hydrogel improved the mechanical resistance of collagen hydrogel without any side effects [91]. Research evidences show that the inspiring mechanical properties of silk are attributed due to its hierarchical properties [92, 93]. Simulation and experimental results of $\beta$ sheet crystallites of silkworm silk show that the stiffness and strength of silk are mainly due to the presence of $\beta$-sheet crystallites. Hydrogen bonds along with intersheet hydrophobic and Van der Waals interactions significantly contribute to the stability of the structures. The exceptional strength of spider silks and silkworm, which exceeds that of steel, is due to beta-sheet nanocrystals. The remarkable strength of silkworm and spider silks, which exceeds that of steel, is due to beta-sheet nanocrystals composed of highly conserved poly-(Gly-Ala) and poly-Ala domains [94].

In vitro, a biomimetic hydrogel containing silk and Lproline showed a considerable improvement in wound healing [95]. The development of a pure silk fibroin hydrogel with a high strength and aligned microgrooved topographic structure has outstanding mechanical characteristics and is extremely strong. The hydrogel biocompatibility also allows them to sustain cell viability [96]. 
2.4. Silk Fibroin Sponges/Blend Films. Wound healing can be enhanced with silk fibroin blends in the form of sponges and films. Porous sponges are important tissue engineering materials, and they have also been made with regenerated silk fibroin solutions $[97,98]$. Sponge scaffolds do provide a network of linked pores with a large surface area inside a predetermined three-dimensional volume, allowing for tissue ingrowth and cell adhesion. The silk/duck feet collagen hybrid sponge, according to Lee et al., could be employed as a dermal substitute for full-thickness skin abnormalities [60]. Liu et al. used a freeze-drying process to create a silk fibroin sponge for the controlled release of neurotensinloaded gelatin microspheres in the treatment of diabetic foot ulcers [99]. The neurotensin-releasing scaffold demonstrated a good drug delivery system and wound dressing material over a 28-day posttreatment follow-up. This increased fibroblast accumulation, wound closure, and granulation of tissues at wound site, which expedited wound healing in diabetic foot ulcers with little scar formation [99]. Padol et al. showed that silk fibroin film, as a unique wound healing material, is extremely effective when combined with epidermal growth factor for acute wound healing [99] (Table 1). In rats, silk films were used to cure full-thickness skin wounds, and they showed faster healing and less inflammatory response than typical porcine-based wound dressings [100].

2.5. Wound Healing Mechanism of Silk Fibroin. The NF- $\kappa \mathrm{B}$ signalling pathway is used by silk fibroin to speed up wound healing [103]. Through complicated signalling pathways, $\mathrm{NF}-\kappa \mathrm{B}$ governs different cell behaviours such as proliferation, adhesion, clearance of reactive oxygen species, and inflammation. As a result, NF- $\kappa \mathrm{B}$ signalling is thought to be important in the healing of diverse wounds such as corneal epithelial wounds [104]. In the silk fibroin-induced cells, there was an increase in the expression of tumour necrosis factor receptor (TNFR) and Toll-like receptors (TLRs), two critical mediators of NF- $\kappa \mathrm{B}$. They also mediated a varied range of protein expression which regulate the healing of wounds and affected by NF- $\kappa \mathrm{B}$ like epidermal growth factor (EGF), fibronectin, vascular endothelial growth factor (VEGF), vimentin, IL-10 (interleukin-10), IL-1b, transforming growth factor (TGF), and cyclin. David. Park et al. (2019) determined that silk fibroin enhanced wound healing by altering the expression of proteins involved in the remodelling and proliferation phases by stimulating NF- $\kappa \mathrm{B}$ signalling (Figure 4) [103].

According to Aykac et al., silk fibroin had a protective effect in a rat model of burn injury by inactivating the apoptotic pathway [101]. Several complex cellular signalling pathways like Wnt and Notch signalling [105], transforming growth factor beta $(\mathrm{TGF} \beta)$ signalling $[105,106]$, mitogen-activated protein kinase (MAPK) signalling [107], and AKT/mTOR signalling [108] take place in a tightly coordinated cascade to heal the wound during the wound healing process. MAPK signalling [109] and AKT/mTOR signalling [108] are two cellular pathways that play a role in wound healing.

2.6. Summary and Future Perspectives. Silk fibroin, due to their credible biocompatibility, significantly lowers biodeg- radation rates compared to other materials, is of userfriendly nature, is easily available, and has least immune response to host tissue which has attracted intense interest in recent decades for various amazing biomedical applications including wound healing. In various wound healing applications, it has been found to be a potential biomaterial in several forms, including solution, films, electrospun silk fibroin nanofibre mats, hydrogels, hydrocolloid dressings, and sponges. Because of the favourable findings obtained in vitro and in vivo, the prospects of employing fibroin alone and in blends in wound healing are highly promising. Electrospun silk fibroin techniques loaded with or without antibacterial agents are predicted to be the most effective silk fibroin-based skin substitute in future clinical trials. To construct a novel array of silk fibroin-based biomaterials for treatment of different types of wound healing, further study is required to investigate the mechanistic basis for silk fibroin on the wound. According to Belda Marin et al. [111] in a review, the behaviour of the biomaterials with ageing and liberating the inorganic phase is detrimental to find out the long-term stability of the scaffolds. Furthermore, more studies on the interaction between organic and inorganic phase is warranted. Only very few studies are available depicting the secondary structural changes of silk fibroin following after the inorganic phase interaction, which has to be studied in detail to elucidate the mechanism. The functional groups present in silk fibroin could be utilized for covalent bond formation with inorganic phase, which may give insight on scaffold designing with specific patterns.

\section{Conflicts of Interest}

The authors declare that they have no conflicts of interest.

\section{Acknowledgments}

The support provided by the Department of Biotechnology, Ministry of Science and Technology, Government of India (to Dr. Senthilkumar Rajagopal; No.: BT/RLF/Reentry/42/2012) to complete this manuscript in a successful manner is gratefully acknowledged.

\section{References}

[1] S. Gupta, H. Alrabaiah, M. Christophe, M. Rahimi-Gorji, P. D. S. Nadeem, and A. Bit, "Evaluation of silk-based bioink during pre and post3Dbioprinting: a review," Journal of Biomedical Materials Research Part B: Applied Biomaterials., vol. 109, no. 2, pp. 279-293, 2021.

[2] B. K. Murugesh, "13- Silk from silkworms and spiders as high-performance fibers," in Structure and Properties of High-Performance Fibers, G. Bhat, Ed., pp. 327-366, Woodhead Publishing, Oxford, 2017.

[3] C. Vepari and D. Kaplan, "Silk as a biomaterial," Progress in polymer science, vol. 32, no. 8-9, pp. 991-1007, 2007.

[4] I. Belhaj Khalifa, N. Ladhari, and M. Touay, "Application of sericin to modify textile supports," Journal of the Textile Institute, vol. 103, no. 4, pp. 370-377, 2012.

[5] S. Kundu, Silk Biomaterials for Tissue Engineering and Regenerative Medicine, Elsevier Science, 2014. 
[6] G. H. Altman, F. Diaz, C. Jakuba et al., "Silk-based biomaterials," Biomaterials, vol. 24, no. 3, pp. 401-416, 2003.

[7] Z. Wang, Y. Zhang, J. Zhang et al., "Exploring natural silk protein sericin for regenerative medicine: an injectable, photoluminescent, cell-adhesive 3D hydrogel," Scientific Reports, vol. 4, no. 1, p. 7064, 2014.

[8] S. Inoue, K. Tanaka, F. Arisaka, S. Kimura, K. Ohtomo, and S. Mizuno, "Silk fibroin of Bombyx mori is secreted, assembling a high molecular mass elementary unit consisting of $\mathrm{H}$-chain, L-chain, and P25, with a 6:6:1 molar ratio," Journal of Biological Chemistry, vol. 275, no. 51, pp. 40517-40528, 2000.

[9] L.-D. Koh, Y. Cheng, C.-P. Teng et al., "Structures, mechanical properties and applications of silk fibroin materials," Progress in Polymer Science, vol. 46, pp. 86-110, 2015.

[10] S. Ling, W. Chen, Y. Fan et al., "Biopolymer nanofibrils: structure, modeling, preparation, and applications," Progress in Polymer Science, vol. 85, pp. 1-56, 2018.

[11] Q. Yu, H. Wang, K. Wei et al., "A review of structure construction of silk fibroin biomaterials from single structures to multi-level structures," International Journal of Molecular Sciences, vol. 18, no. 3, p. 237, 2017.

[12] K. Shimura, "Chemical composition and biosynthesis of silk proteins," Experientia, vol. 39, no. 5, pp. 455-461, 1983.

[13] B. Kundu, R. Rajkhowa, S. C. Kundu, and X. Wang, "Silk fibroin biomaterials for tissue regenerations," Advanced drug delivery reviews, vol. 65, no. 4, pp. 457-470, 2013.

[14] P. Zeplin, N. Maksimovikj, M. Jordan et al., "Spider silk coatings as a bioshield to reduce periprosthetic fibrous capsule formation," Advanced Functional Materials, vol. 24, no. 18, pp. 2658-2666, 2014.

[15] M. J. Rodriguez, J. Brown, J. Giordano, S. J. Lin, F. G. Omenetto, and D. L. Kaplan, "Silk based bioinks for soft tissue reconstruction using 3-dimensional (3D) printing with in vitro and in vivo assessments," Biomaterials, vol. 117, pp. 105-115, 2017.

[16] A. E. Thurber, F. G. Omenetto, and D. L. Kaplan, "In vivo bioresponses to silk proteins," Biomaterials, vol. 71, pp. 145-157, 2015.

[17] W. L. Stoppel, C. E. Ghezzi, S. L. McNamara, L. D. B. III, and D. L. Kaplan, "Clinical applications of naturally derived biopolymer-based scaffolds for regenerative medicine," Annals of Biomedical Engineering, vol. 43, no. 3, pp. 657-680, 2015.

[18] N. Shankhwar, M. Kumar, B. B. Mandal, and A. Srinivasan, "Novel polyvinyl alcohol-bioglass $45 \mathrm{~S} 5$ based composite nanofibrous membranes as bone scaffolds," Materials Science and Engineering: C, vol. 69, pp. 1167-1174, 2016.

[19] M. Floren, W. Bonani, A. Dharmarajan, A. Motta, C. Migliaresi, and W. Tan, "Human mesenchymal stem cells cultured on silk hydrogels with variable stiffness and growth factor differentiate into mature smooth muscle cell phenotype," Acta Biomaterialia, vol. 31, pp. 156-166, 2016.

[20] W. Sun, A. Motta, Y. Shi et al., "Co-culture of outgrowth endothelial cells with human mesenchymal stem cells in silk fibroin hydrogels promotes angiogenesis," Biomedical Materials, vol. 11, no. 3, article 035009, 2016.

[21] J. Melke, S. Midha, S. Ghosh, K. Ito, and S. Hofmann, "Silk fibroin as biomaterial for bone tissue engineering," Acta Biomaterialia, vol. 31, pp. 1-16, 2016.

[22] T. Asakura, Y. Suzuki, Y. Nakazawa, G. P. Holland, and J. L. Yarger, "Elucidating silk structure using solid-state NMR," Soft Matter, vol. 9, no. 48, pp. 11440-11450, 2013.
[23] F. Mottaghitalab, H. Hosseinkhani, M. A. Shokrgozar, C. Mao, M. Yang, and M. Farokhi, "Silk as a potential candidate for bone tissue engineering," Journal of Controlled Release, vol. 215, pp. 112-128, 2015.

[24] M. Farokhi, F. Mottaghitalab, S. Samani et al., "Silk fibroin/hydroxyapatite composites for bone tissue engineering," Biotechnology advances, vol. 36, no. 1, pp. 68-91, 2018.

[25] M. Farokhi, F. Mottaghitalab, J. Hadjati et al., "Structural and functional changes of silk fibroin scaffold due to hydrolytic degradation," Journal of Applied Polymer Science, vol. 131, no. 6, 2014.

[26] X. Hu, K. Shmelev, L. Sun et al., "Regulation of silk material structure by temperature-controlled water vapor annealing," Biomacromolecules, vol. 12, no. 5, pp. 1686-1696, 2011.

[27] C. Correia, S. Bhumiratana, L.-P. Yan et al., "Development of silk-based scaffolds for tissue engineering of bone from human adipose-derived stem cells," Acta Biomaterialia, vol. 8, no. 7, pp. 2483-2492, 2012.

[28] S.-H. Park, E. S. Gil, H. Shi, H. J. Kim, K. Lee, and D. L. Kaplan, "Relationships between degradability of silk scaffolds and osteogenesis," Biomaterials, vol. 31 , no. 24, pp. 6162$6172,2010$.

[29] Q. Lu, X. Hu, X. Wang et al., "Water-insoluble silk films with silk I structure," Acta Biomaterialia, vol. 6, no. 4, pp. 13801387, 2010.

[30] H. Zhang, J. Magoshi, M. Becker, J. Chen, and R. Matsunaga, "Thermal properties of Bombyx mori silk fibers," Journal of Applied Polymer Science, vol. 86, no. 8, pp. 1817-1820, 2002.

[31] A. Motta, L. Fambri, and C. Migliaresi, "Regenerated silk fibroin films: thermal and dynamic mechanical analysis," Macromolecular Chemistry and Physics-MACROMOL CHEM PHYSICS, vol. 203, no. 10-11, pp. 1658-1665, 2002.

[32] A. Martel, M. Burghammer, R. J. Davies, and C. Riekel, "Thermal behavior of Bombyx mori silk: evolution of crystalline parameters, molecular structure, and mechanical properties," Biomacromolecules, vol. 8, no. 11, pp. 3548-3556, 2007.

[33] L. F. Drummy, D. M. Phillips, M. O. Stone, B. L. Farmer, and R. R. Naik, "Thermally induced $\alpha$-helix to $\beta$-sheet transition in regenerated silk fibers and films," Biomacromolecules, vol. 6, no. 6, pp. 3328-3333, 2005.

[34] R. L. Moy, A. Lee, and A. Zalka, "Commonly used suture materials in skin surgery," American Family Physician, vol. 44, no. 6, pp. 2123-2128, 1991.

[35] X. Y. Luan, Y. Wang, X. Duan et al., "Attachment and growth of human bone marrow derived mesenchymal stem cells on regenerated antheraea pernyi silk fibroin films," Biomedical materials (Bristol, England), vol. 1, no. 4, pp. 181-187, 2006.

[36] A. Schneider, X. Y. Wang, D. L. Kaplan, J. A. Garlick, and C. Egles, "Biofunctionalized electrospun silk mats as a topical bioactive dressing for accelerated wound healing," Acta Biomaterialia, vol. 5, no. 7, pp. 2570-2578, 2009.

[37] M. Li, M. Ogiso, and N. Minoura, "Enzymatic degradation behavior of porous silk fibroin sheets," Biomaterials, vol. 24, no. 2, pp. 357-365, 2003.

[38] S. Yan, C. Zhao, X. Wu, Q. Zhang, and M. Li, "Gelation behavior of Antheraea pernyi silk fibroin," Science China Chemistry, vol. 53, no. 3, pp. 535-541, 2010.

[39] M. Puerta, M. S. Peresin, and A. Restrepo-Osorio, "Effects of chemical post-treatments on structural and physicochemical properties of silk fibroin films obtained from silk fibrous 
waste," Frontiers in Bioengineering and Biotechnology, vol. 8, article 523949, 2020.

[40] D. Naskar, R. R. Barua, A. K. Ghosh, and S. Kundu, "Introduction to silk biomaterials," in Silk biomaterials for tissue engineering and regenerative medicine, pp. 3-40, Woodhead Publishing, 2014.

[41] A. J. Singer and R. A. F. Clark, "Cutaneous wound healing," New England Journal of Medicine, vol. 341, no. 10, pp. 738746, 1999.

[42] A. C. O. Gonzalez, T. F. Costa, Z. A. Andrade, and A. R. A. P. Medrado, "Wound healing - a literature review," Anais Brasileiros de Dermatologia, vol. 91, no. 5, pp. 614-620, 2016.

[43] K. S. Midwood, L. V. Williams, and J. E. Schwarzbauer, "Tissue repair and the dynamics of the extracellular matrix," The International Journal of Biochemistry \& Cell Biology, vol. 36, no. 6, pp. 1031-1037, 2004.

[44] G. C. Gurtner, S. Werner, Y. Barrandon, and M. T. Longaker, "Wound repair and regeneration," Nature, vol. 453, no. 7193, pp. 314-321, 2008.

[45] F. M. Wood, "Skin regeneration: the complexities of translation into clinical practise," The International Journal of Biochemistry \& Cell Biology, vol. 56, pp. 133-140, 2014.

[46] J. M. Reinke and H. Sorg, "Wound repair and regeneration," European Surgical Research, vol. 49, no. 1, pp. 39-45, 2012.

[47] M. W. Ferguson, "Wound healing-scar wars," The Ulster medical journal, vol. 67, Supplement 1, pp. 37-40, 1998.

[48] W. A. Border and E. Ruoslahti, "Transforming growth factorbeta in disease: the dark side of tissue repair," The Journal of Clinical Investigation, vol. 90, no. 1, pp. 1-7, 1992.

[49] V. Agarwal, F. M. Wood, M. Fear, and K. S. Iyer, "Polymeric Nanofibre scaffold for the delivery of a transforming growth factor $\beta 1$ inhibitor," Australian Journal of Chemistry, vol. 70, no. 3, pp. 280-285, 2016.

[50] S.-Y. Ong, J. Wu, S. M. Moochhala, M.-H. Tan, and J. Lu, "Development of a chitosan-based wound dressing with improved hemostatic and antimicrobial properties," Biomaterials, vol. 29, no. 32, pp. 4323-4332, 2008.

[51] D. Wyatt, D. N. McGowan, and M. P. Najarian, "Comparison of a hydrocolloid dressing and silver sulfadiazine cream in the outpatient management of second-degree burns," The Journal of trauma, vol. 30, no. 7, pp. 857-865, 1990.

[52] D. Konrad, M. Tsunoda, K. Weber, S. J. Corney, and L. Ullmann, "Effects of a topical silver sulfadiazine polyurethane dressing (Mikacure) on wound healing in experimentally infected wounds in the pig. A pilot study," Journal of Experimental Animal Science, vol. 42, no. 1, pp. 31-43, 2002.

[53] I. M. Vassallo and C. Formosa, "Comparing calcium alginate dressings to vacuum-assisted closure: a clinical trial," Wounds: a compendium of clinical research and practice, vol. 27, no. 7, pp. 180-190, 2015.

[54] H. Powell, D. Supp, and S. Boyce, "Influence of electrospun collagen on wound contraction of engineered skin substitutes," Biomaterials, vol. 29, no. 7, pp. 834-843, 2008.

[55] M. T. Sultan, J. Y. Jeong, Y. B. Seo et al., "Fabrication and characterization of the porous duck's feet collagen sponge for wound healing applications," Journal of Biomaterials Science, Polymer Edition, vol. 29, no. 7-9, pp. 960-971, 2018.

[56] R. Uppal, G. N. Ramaswamy, C. Arnold, R. Goodband, and Y. Wang, "Hyaluronic acid nanofiber wound dressing-production, characterization, and in vivo behavior," Journal of biomedical materials research Part B, Applied biomaterials, vol. 97, no. 1, pp. 20-29, 2011.

[57] F. M. Wood, "Chapter 73- Therapeutic applications: tissue engineering of skin," in Principles of Regenerative Medicine, A. Atala, R. Lanza, A. G. Mikos, and R. Nerem, Eds., pp. 1281-1295, Academic Press, Boston, Third Edition edition, 2019.

[58] S. Seaman, "Dressing selection in chronic wound management," Journal of the American Podiatric Medical Association, vol. 92, no. 1, pp. 24-33, 2002.

[59] M. Gholipourmalekabadi, S. Sapru, A. Samadikuchaksaraei, R. L. Reis, D. L. Kaplan, and S. C. Kundu, "Silk fibroin for skin injury repair: where do things stand?," Advanced drug delivery reviews, vol. 153, pp. 28-53, 2020.

[60] O. J. Lee, H. W. Ju, J. H. Kim et al., "Development of artificial dermis using 3D electrospun silk fibroin nanofiber matrix," Journal of biomedical nanotechnology, vol. 10, no. 7, pp. 1294-1303, 2014.

[61] E. J. Chung, H. W. Ju, H. J. Park, and C. Park, “Three-layered scaffolds for artificial esophagus using poly( $\varepsilon$-caprolactone) nanofibers and silk fibroin: an experimental study in a rat model," Journal of Biomedical Materials Research Part A, vol. 103, no. 6, pp. 2057-2065, 2015.

[62] C. Martínez-Mora, A. Mrowiec, E. García-Vizcaíno, A. Alcaraz, J. Cenis, and F. Nicolás, "Fibroin and sericin from Bombyx mori silk stimulate cell migration through upregulation and phosphorylation of c-Jun," Plo S one, vol. 7, no. 7, article e42271, 2012.

[63] Y. R. Park, M. T. Sultan, H. J. Park et al., "NF- $\kappa$ B signaling is key in the wound healing processes of silk fibroin," Acta Biomaterialia, vol. 67, pp. 183-195, 2018.

[64] W. Abdel-Naby, B. Cole, A. Liu et al., "Treatment with solubilized silk-derived protein (SDP) enhances rabbit corneal epithelial wound healing," PloS one, vol. 12, no. 11, article e0188154, 2017.

[65] M. Gholipourmalekabadi, M. Mozafari, M. Bandehpour et al., "Optimization of nanofibrous silk fibroin scaffold as a delivery system for bone marrow adherent cells: in vitro and in vivo studies," Biotechnology and applied biochemistry, vol. 62, no. 6, pp. 785-794, 2015.

[66] M. Gholipourmalekabadi, A. Samadikuchaksaraei, A. M. Seifalian et al., "Silk fibroin/amniotic membrane 3D bi-layered artificial skin," Biomedical materials (Bristol, England), vol. 13, no. 3, article 035003, 2018.

[67] Y. R. Park, H. W. Ju, J. M. Lee et al., “Three-dimensional electrospun silk-fibroin nanofiber for skin tissue engineering," International journal of biological macromolecules, vol. 93, no. Part B, pp. 1567-1574, 2016.

[68] O. O. Ige, L. E. Umoru, and S. Aribo, "Natural products: a minefield of biomaterials," ISRN Materials Science, vol. 2012, Article ID 983062, 20 pages, 2012.

[69] H. Rodríguez-Tobías, G. Morales, and D. Grande, "Comprehensive review on electrospinning techniques as versatile approaches toward antimicrobial biopolymeric composite fibers," Materials Science and Engineering: C, vol. 101, pp. 306-322, 2019.

[70] S. Meka, S. Kumar Verma, V. Agarwal, and K. Chatterjee, "In situ silication of polymer nanofibers to engineer multibiofunctional composites," Chemistry Select, vol. 3, no. 13, pp. 3762-3773, 2018. 
[71] L. Krishna, S. Nilawar, M. Ponnalagu et al., "Fiber diameter differentially regulates function of retinal pigment and corneal epithelial cells on nanofibrous tissue scaffolds," ACS Applied Bio Material, vol. 3, no. 2, pp. 823-837, 2020.

[72] S. R. K. Meka, V. Agarwal, and K. Chatterjee, "In situ preparation of multicomponent polymer composite nanofibrous scaffolds with enhanced osteogenic and angiogenic activities," Materials science \& engineering C, Materials for biological applications, vol. 94, pp. 565-579, 2019.

[73] X. Zong, H. Bien, C. Chung et al., "Electrospun fine-textured scaffolds for heart tissue constructs," Biomaterials, vol. 26, no. 26, pp. 5330-5338, 2005.

[74] P. X. Ma and R. Zhang, "Synthetic nano-scale fibrous extracellular matrix," Journal of Biomedical Materials Research, vol. 46, no. 1, pp. 60-72, 1999.

[75] T. Hodgkinson, X.-F. Yuan, and A. Bayat, "Electrospun silk fibroin fiber diameter influences in vitro dermal fibroblast behavior and promotes healing of ex vivo wound models," Journal of Tissue Engineering, vol. 5, 2014.

[76] A. S. Badami, M. R. Kreke, M. S. Thompson, J. S. Riffle, and A. S. Goldstein, "Effect of fiber diameter on spreading, proliferation, and differentiation of osteoblastic cells on electrospun poly(lactic acid) substrates," Biomaterials, vol. 27, no. 4, pp. 596-606, 2006.

[77] B. Bondar, S. Fuchs, A. Motta, C. Migliaresi, and C. J. Kirkpatrick, "Functionality of endothelial cells on silk fibroin nets: comparative study of micro- and nanometric fibre size," Biomaterials, vol. 29, no. 5, pp. 561-572, 2008.

[78] E. Suarez, F. Syed, T. A. Rasgado, A. Walmsley, P. Mandal, and A. Bayat, "Skin equivalent tensional force alters keloid fibroblast behavior and phenotype," Wound repair and regeneration: official publication of the Wound Healing Society [and] the European Tissue Repair Society, vol. 22, no. 5, pp. 557-568, 2014.

[79] E. Suarez, F. Syed, T. Alonso-Rasgado, P. Mandal, and A. Bayat, "Up-regulation of tension-related proteins in keloids: knockdown of Hsp 27, $\alpha 2 \beta 1$-integrin, and PAI-2 shows convincing reduction of extracellular matrix production," Plastic and reconstructive surgery, vol. 131, no. 2, pp. 158e-173e, 2013.

[80] S. Ichihara, Y. Inada, and T. Nakamura, "Artificial nerve tubes and their application for repair of peripheral nerve injury: an update of current concepts," Injury, vol. 39, Supplement 4, pp. 29-39, 2008.

[81] I. V. Yannas, M. Zhang, and M. H. Spilker, "Standardized criterion to analyze and directly compare various materials and models for peripheral nerve regeneration," Journal of biomaterials science Polymer edition, vol. 18, no. 8, pp. 943-966, 2007.

[82] K. Murakami, H. Aoki, S. Nakamura et al., "Hydrogel blends of chitin/chitosan, fucoidan and alginate as healing-impaired wound dressings," Biomaterials, vol. 31, no. 1, pp. 83-90, 2010.

[83] K. H. Bouhadir, K. Y. Lee, E. Alsberg, K. L. Damm, K. W. Anderson, and D. J. Mooney, "Degradation of partially oxidized alginate and its potential application for tissue engineering," Biotechnology Progress, vol. 17, no. 5, pp. 945-950, 2001.

[84] H. Niiyama and Y. Kuroyanagi, "Development of novel wound dressing composed of hyaluronic acid and collagen sponge containing epidermal growth factor and vitamin C derivative," Journal of Artificial Organs, vol. 17, no. 1, pp. 81-87, 2014.
[85] J. A. Burdick and G. D. Prestwich, "Hyaluronic acid hydrogels for biomedical applications," Advanced Materials, vol. 23, no. 12, pp. H41-H56, 2011.

[86] H. W. Ju, O. J. Lee, B. M. Moon et al., "Silk fibroin based hydrogel for regeneration of burn induced wounds," Tissue Engineering and Regenerative Medicine, vol. 11, no. 3, pp. 203-210, 2014.

[87] J. M. Lee, M. T. Sultan, S. H. Kim et al., "Artificial auricular cartilage using silk fibroin and polyvinyl alcohol hydrogel," International journal of molecular sciences, vol. 18, no. 8, p. $1707,2017$.

[88] J. L. Drury and D. J. Mooney, "Hydrogels for tissue engineering: scaffold design variables and applications," Biomaterials, vol. 24, no. 24, pp. 4337-4351, 2003.

[89] S. Kapoor and S. C. Kundu, "Silk protein-based hydrogels: promising advanced materials for biomedical applications," Acta Biomaterialia, vol. 31, pp. 17-32, 2016.

[90] O. Hakimi, D. P. Knight, F. Vollrath, and P. Vadgama, "Spider and mulberry silkworm silks as compatible biomaterials," Composites Part B: Engineering, vol. 38, no. 3, pp. 324-337, 2007.

[91] M. A. de Moraes, E. Paternotte, D. Mantovani, and M. M. Beppu, "Mechanical and biological performances of new scaffolds made of collagen hydrogels and fibroin microfibers for vascular tissue engineering," Macromolecular bioscience, vol. 12, no. 9, pp. 1253-1264, 2012.

[92] A. Nova, S. Keten, N. M. Pugno, A. Redaelli, and M. J. Buehler, "Molecular and nanostructural mechanisms of deformation, strength and toughness of spider silk fibrils," Nano letters, vol. 10, no. 7, pp. 2626-2634, 2010.

[93] X. X. Xia, Z. G. Qian, C. S. Ki, Y. H. Park, D. L. Kaplan, and S. Y. Lee, "Native-sized recombinant spider silk protein produced in metabolically engineered Escherichia coli results in a strong fiber," Proceedings of the National Academy of Sciences of the United States of America, vol. 107, no. 32, pp. 14059-14063, 2010.

[94] S. Keten, Z. Xu, B. Ihle, and M. J. Buehler, "Nanoconfinement controls stiffness, strength and mechanical toughness of $\beta$ sheet crystals in silk," Nature materials, vol. 9, no. 4, pp. 359-367, 2010.

[95] P. Thangavel, B. Ramachandran, R. Kannan, and V. Muthuvijayan, "Biomimetic hydrogel loaded with silk and l-proline for tissue engineering and wound healing applications," Journal of biomedical materials research Part B, Applied biomaterials, vol. 105, no. 6, pp. 1401-1408, 2017.

[96] X. Gu, X. Chen, X. Tang et al., "Pure-silk fibroin hydrogel with stable aligned micropattern toward peripheral nerve regeneration," Nanotechnology Reviews, vol. 10, no. 1, pp. 10-19, 2021.

[97] H. Liu, H. Fan, Y. Wang, S. L. Toh, and J. C. H. Goh, "The interaction between a combined knitted silk scaffold and microporous silk sponge with human mesenchymal stem cells for ligament tissue engineering," Biomaterials, vol. 29, no. 6, pp. 662-674, 2008.

[98] W. Shen, X. Chen, J. Chen et al., "The effect of incorporation of exogenous stromal cell-derived factor- 1 alpha within a knitted silk-collagen sponge scaffold on tendon regeneration," Biomaterials, vol. 31, no. 28, pp. 7239-7249, 2010.

[99] J. Liu, L. Yan, W. Yang et al., "Controlled-release neurotensin-loaded silk fibroin dressings improve wound 
healing in diabetic rat model," Bioactive Materials, vol. 4, pp. 151-159, 2019.

[100] A. Sugihara, K. Sugiura, H. Morita et al., "Promotive effects of a silk film on epidermal recovery from full-thickness skin wounds," Proceedings of the Society for Experimental Biology and Medicine Society for Experimental Biology and Medicine (New York, NY), vol. 225, no. 1, pp. 58-64, 2000.

[101] A. Aykac, B. Karanlik, and A. O. Sehirli, "Protective effect of silk fibroin in burn injury in rat model," Gene, vol. 641, pp. 287-291, 2018.

[102] D. Jao, X. Mou, and X. Hu, "Tissue regeneration: a silk road," Journal of Functional Biomaterial, vol. 7, no. 3, p. 22, 2016.

[103] D. W. Infanger, W. Abdel-Naby, J. J. Kalal, N. B. Paulson, Y. Bai, and B. D. Lawrence, "Silk-Derived Protein-4 (SDP4) inhibits Nuclear Factor Kappa B (NF- $\kappa$ B) inflammatory signaling that underlies Dry Eye Disease (DED)," Investigative Opthomology and Visual Science, vol. 60, no. 9, p. 2820, 2019.

[104] L. Wang, X. Wu, T. Shi, and L. Lu, "Epidermal growth factor (EGF)-induced corneal epithelial wound healing through nuclear factor $\kappa \mathrm{B}$ subtype-regulated CCCTC binding factor (CTCF) activation," J Biol Chem., vol. 288, no. 34, pp. 24363-24371, 2013.

[105] Y. Shi, B. Shu, R. Yang et al., "Wnt and notch signaling pathway involved in wound healing by targeting c-Myc and Hes 1 separately," Stem Cell Research \& Therapy, vol. 6, no. 1, p. 120, 2015.

[106] F. Cheng, Y. Shen, P. Mohanasundaram et al., "Vimentin coordinates fibroblast proliferation and keratinocyte differentiation in wound healing via TGF- $\beta$-Slug signaling," Proceedings of the National Academy of Sciences of the United States of America, vol. 113, no. 30, pp. E4320-E4327, 2016.

[107] J. Chen, Y. Chen, Y. Chen et al., "Epidermal CFTR suppresses MAPK/NF- $\kappa \mathrm{B}$ to promote cutaneous wound healing," Cellular physiology and biochemistry: international journal of experimental cellular physiology, biochemistry, and pharmacology, vol. 39, no. 6, pp. 2262-2274, 2016.

[108] W. Xing, W. Guo, C. H. Zou et al., “Acemannan accelerates cell proliferation and skin wound healing through AKT/mTOR signaling pathway," Journal of dermatological science, vol. 79, no. 2, pp. 101-109, 2015.

[109] T. Thuraisingam, Y. Z. Xu, K. Eadie et al., "MAPKAPK-2 signaling is critical for cutaneous wound healing," The Journal of investigative dermatology, vol. 130, no. 1, pp. 278-286, 2010.

[110] M. T. Sultan, O. J. Lee, S. H. Kim, H. W. Ju, and C. H. Park, "Silk fibroin in wound healing process," Advances in Experimental Medicine and Biology, vol. 1077, pp. 115-126, 2018.

[111] C. Belda Marín, V. Fitzpatrick, D. L. Kaplan, J. Landoulsi, E. Guénin, and C. Egles, "Silk polymers and nanoparticles: a powerful combination for the design of versatile biomaterials," Frontiers in Chemistry, vol. 8, article 604398, 2020. 